SPECIAL ISSUE ARTICLE

\title{
Queen Bees and Alpha Males: Are successful women more competitive than successful men?
}

\author{
Klea Faniko, Naomi Ellemers \& Belle Derks \\ Faculty of Social and Behavioural Sciences, Utrecht University, Utrecht, The Netherlands
}

\author{
Correspondence \\ Klea Faniko, Utrecht University, Faculty of \\ Social and Behavioural Sciences, Utrecht, \\ The Netherlands. \\ E-mail: k.faniko@uu.nl
}

Received: 6 August 2015

Accepted: 3 March 2016

http://dx.doi.org/10.1002/ejsp.2198

\begin{abstract}
Two studies carried out in Switzerland examined different explanations for the "Queen Bee (QB)-phenomenon." In Study $1(N=315)$, female managers (vs. subordinates) identified with successful women and supported measures that would benefit these women-even though they are their direct competitors. However, they were disinclined to identify with women who put their family first, viewed themselves as different (more masculine) than junior women, and were reluctant to endorse measures to support them. Study $2(N=277)$ compared QB-responses of women to Alpha Male (AM) responses of men. We found evidence of QB and AM effects: both female and male managers rated their own masculinity as higher than that of same-gender junior colleagues. Compared to their male colleagues, women in managerial positions were more inclined to identify with successful same-gender colleagues. This counters explanations for the QB effect as being due to increased competitiveness of successful women.
\end{abstract}

Although the benefits of gender diversity in organizational management have been clearly documented, women remain underrepresented in leadership positions (see Barreto, Ryan, \& Schmitt, 2009; Ellemers, 2014, for reviews). Researchers have tried to identify the factors responsible for women's underrepresentation in the workplace. Initial efforts addressed the role of blatant and subtle gender bias, among men in particular (e.g., Barreto \& Ellemers, 2013). More recently, a growing body of research has documented that women who have reached high positions sometimes do not support the advancement of other women (Derks, Van Laar, \& Ellemers, in press; Ellemers, Rink, Derks, \& Ryan, 2012). This is generally referred to as the "Queen Bee (QB)-phenomenon" and has been taken as indicating that women are to blame for their underrepresentation in leadership positions, arguing that senior women are the ones who diminish the career opportunities for other women (see Ellemers et al., 2012, for a discussion). In this contribution, we argue that the mechanism is more complex than that. In prior work, we established that the emergence of QB-responses depends on women's own career experiences; it is triggered when low gender-identified women are confronted with gender-based treatment at work (Derks, Ellemers, Van Laar, \& De Groot, 2011; Derks, Van Laar, Ellemers, \& De Groot, 2011). The present work addresses first whether the QB-phenomenon implies that successful career women are highly competitive toward all their female colleagues or whether they differentiate themselves only from junior women. Second, we aim to determine whether response patterns that characterize the QB-phenomenon are specific to women in managerial positions, or whether similar mechanisms (Alpha Male (AM) responses) also occur among men as they advance in their career.

\section{The Origins of the QB-Phenomenon}

The QB effect refers to the phenomenon that women who have been successful in male-dominated organizations sometimes behave in ways that impede rather than help the advancement of other women. Previous research has identified three indicators of QB-responses. First, QBs have been found to distance themselves from their women colleagues, for instance, by rating their own career commitment as higher than that of other women. Second, QBs try to assimilate into the higher-status group (i.e., men) by emphasizing their stereotypically masculine characteristics and leadership qualities. Finally, QBs have been found to legitimize the current status quo in which men have higher status than women by opposing policies that would improve the standing of women (Derks et al., in press; Derks, Van Laar, et al., 2011; Derks, Van Laar, Ellemers, \& Raghoe, 2015; Faniko, 2015; Faniko, Lorenzi-Cioldi, Buschini, \& Chatard, 2008, 2012; Faniko et al., 2015; Ng \& Chiu, 2001).

Some have suggested that these reactions are inherent to women and a direct manifestation of female competition in the workplace. These approaches argue that there is generally more competition between women 
than between men and that women prevent other women from being successful (see Sheppard \& Aquino, 2013, for a discussion). By contrast, our prior research has demonstrated the context-dependence of the QB-phenomenon. Rather than indicating the way women generally respond to each other, it is a consequence of negative discrimination-related career experiences women tend to encounter in male-dominated organizations, which does not emerge when men and women are treated equally in the workplace (Derks, Ellemers, et al., 2011; Derks, Van Laar, et al., 2011).

In line with social identity theory (Tajfel $\&$ Turner, 1986), we argue that the QB-phenomenon should be seen as an individual mobility response to the identity threat that women may encounter at work. Women sometimes-for instance, when they are not particularly identified with their gender group — try to improve their own opportunities for career success, instead of striving to improve outcomes for women more generally. They do this by distancing themselves from other women and the negative work-related stereotypes that are associated with them. Indeed, a study among women managers (Derks, Ellemers, et al., 2011) revealed two ingredients that contribute to the QB effect: Women were most likely to distance themselves from other women (by describing themselves in stereotypically masculine terms and devaluing the career ambitions of other women) when they (i) experienced low identification with women at work and (ii) had experienced a relatively high degree of gender-based discrimination. Establishing the causal nature of the effect of gender bias on QB-responses, an experimental study showed that senior police women with low gender identification distanced themselves from other women, denied gender discrimination in their professional field, and opposed programs aimed at improving junior women's professional opportunities only when they had been asked to describe an experience in which they were treated on the basis of gender stereotypes (Derks, Van Laar, et al., 2011). Identical self-group distancing responses were found among weakly identified ethnic minority employees after they were reminded of the discrimination they had encountered at work (Derks et al., 2015). Thus, empirical evidence clearly indicates that QB-responses are triggered by women's discrimination experiences, rather than being a sign of increased competitiveness among professional women more generally.

\section{Do Women Managers Show QB-Responses Toward All Women?}

Theory and research has tended to treat women as a unified social category, contrasting the tendency to distance the self from other women with the willingness to identify with and support other women in general (e.g., Derks, Ellemers, et al., 2011). In the present work, we refine this analysis by distinguishing between responses displayed toward different subgroups of women. We propose that women in managerial positions do not necessarily distance themselves from all other women. Instead, they should be most inclined to dissociate from women who are most likely to confirm negative gender stereotypes-that is, junior women-leading them to report low identification with this subgroup of women in particular. At the same time, they may be quite willing to identify with and support women in similar positions as themselves; such women have already disconfirmed gender stereotypes, have undergone similar career experiences, and have made similar non traditional life choices as themselves.

If our reasoning is valid, women displaying QB-responses to junior women may be quite willing to identify with and support other women who resemble them in terms of career success and life priorities, even if these are their most direct competitors. By contrast, if the QB-phenomenon reflects increased competitiveness among female managers, we should find a more generic pattern of self-group distancing and a lack of support of measures benefiting other women, regardless of which subgroup of women is addressed.

We examine evidence for these two explanations of the QB-phenomenon in two studies, by comparing responses to different subgroups of women. If the QBphenomenon reflects attempts to emphasize differences between the self and gender stereotypical women, women in managerial positions should mainly show evidence of self-group distancing and reluctance to support other women, when considering women who are in a more junior position or have different life priorities, but they should be quite willing to identify with and support other women who have undergone similar career experiences as they have. If the QB-phenomenon results from increased competitiveness among successful women, we should find evidence of self-group distancing and reluctance to support other women regardless of their professional position and career experiences.

\section{Do QBs Respond Differently Than Male Managers?}

Prior work has examined responses of women with different career experiences, without validating whether these are unique for female managers or whether similar responses can be observed among male managers (for an exception, see Ellemers, van den Heuvel, de Gilder, Maass, \& Bonvini, 2004). At present, it is unclear whether QB-responses should be seen as indicating increased competitiveness among successful women in particular. We cannot exclude the possibility that the tendency to see the self as more masculine and career oriented than junior counterparts is characteristic of successful individuals regardless of gender. Indeed, it is quite possible that for men a similar AM phenomenon can be observed, whereby men in positions of power also emphasize their masculinity and work commitment relative to more junior men and are reluctant to identify with them. If, however, QB-responses indicate an increased sense of 
competitiveness among successful women, self-group distancing should only be observed among women, but not men, who have climbed the organizational ladder. The present work thus also extends prior research by comparing the responses displayed by women by those of men in managerial and subordinate positions.

\section{Study 1}

The main goal of Study 1 is to examine whether the QB-phenomenon implies an increased sense of competitiveness among women managers toward other women or if it should be seen as a way to distinguish the self from the subgroup of junior women or those who have made different life choices. To this end, we will compare how women in managerial versus subordinate positions differ in responses associated with the QBphenomenon. That is, we examine ratings of their own career commitment and masculinity compared to the way they rate different groups of other women and assess their willingness to support gender quotas targeting different subgroups of women. We compare QB-responses to junior women at an early career stage with those directed toward women at the same senior level. We test whether QB level of identification with other women at work predicts their willingness to identify with different subgroups of women.

\section{Participants and Design}

The study was conducted among 315 female employees (age 19 to 63 years; $M=41.07, S D=11.28$ ) from different sectors in the French part of Switzerland. Participants were contacted at their workplace and were invited to complete an online survey (10-20 minutes). In terms of hierarchical position, 94 participants were in managerial positions; 221 participants, in subordinate positions; and on average, they reported 20 years of work experience. First, participants reported on their identification with different subgroups of women, their personal career commitment, and masculinity. Then, we manipulated participants' target of reference. In the target junior women condition, the participants were invited to think about young female colleagues who had just started their career. In the target same level women condition, participants were invited to think about female colleagues who have reached the same hierarchical level as themselves. Next, participants were asked to estimate the career commitment and masculinity of one of these subgroups of colleagues, depending on experimental condition. Finally, participants were asked to indicate their support of gender quotas benefiting the specific subgroup of women they had been asked to consider, depending on experimental condition (i.e., either more junior women or women at the same hierarchical level).

\section{Measures}

All items in the questionnaire were measured by using 7-point Likert scales ranging from $1=$ strongly disagree to $7=$ strongly agree.

Identification with different subgroups of women. Five items assessed participants' identification with different subgroups of women. Identification with junior women was assessed with the following two items: "I feel close to junior female colleagues at the beginning of their career" and "I feel close to female colleagues holding subordinate positions" $(r=.54, p<.001)$. Identification with women in managerial positions was assessed with two items: "I feel close to female colleagues holding positions of responsibility" and "I feel close to female colleagues who have succeeded in their career" $(r=.77, p<.001)$. Finally, we assessed identification with other women who had made gender stereotypical life choices with the following item: "I feel close to female colleagues who prioritize their family life."

QB-responses. As in previous studies (e.g., Derks, Ellemers, et al., 201 1; Ellemers et al., 2004), we assessed three indicators of the QB-phenomenon. First, we examined whether women in managerial positions rated their own career commitment as higher than that of other junior women. Second, we tested whether they rated themselves in more masculine terms than other junior women. Third, we examined support of gender quotas (benefiting either junior women or women at the same organizational level, depending on experimental condition).

Career commitment. All participants were asked to report their personal career commitment with three items $(\alpha=.82)$ : "My career is one of the most important things in my life," "The ambitions in my life mainly have to do with my career," and "My career plays a central role in my life" (Ellemers, De Gilder, \& Van den Heuvel, 1998).

Masculinity. To assess self-perceived masculinity, we selected four items from Bem's Sex Role Inventory (Bem, 1974) and asked participants to indicate to what degree stereotypically masculine traits (e.g., dominant, assertive, having leadership abilities, willing to take risks) described themselves $(\alpha=.87)$.

At this point of the study, half of the participants were invited to think about junior women at an early career stage (target junior women condition) and half of them were invited to think about female colleagues at the same hierarchical level as themselves (target same level women condition) and report that subgroup's perceived career commitment $(\alpha=.91)$ and masculinity $(\alpha=.86$; the same items were adjusted to focus on one of these groups of women). 
Table 1. Results of MANOVAs examining statistical differences for identification with different subgroups of women as predicted by women's hierarchical position (managerial vs. subordinate), Study 1

\begin{tabular}{lcc}
\hline & Women in managerial positions & Women in subordinate positions \\
\hline Junior women at an early career stage & $4.51^{\mathrm{a}}(1.45)$ & $4.49^{\mathrm{a}}(1.49)$ \\
Successful women & $4.98^{\mathrm{b}}(1.45)$ & $4.17^{\mathrm{c}}(1.52)$ \\
Women who prioritize family life & $4.62^{\mathrm{ab}}(1.82)$ & $5.29^{\mathrm{d}}(1.62)$ \\
\hline
\end{tabular}

Note: Means with different superscripts differ significantly from one another $(p>.05)$. For each dependent variable, between-participants comparisons are made within rows, and within-participants comparisons are made within columns.

Support for gender quotas. Next, we assessed participants' attitudes toward gender quotas targeting different subgroups of women. In the target junior women condition, participants read that gender quotas would allow junior female colleagues to make progress in their career. In the target same level women condition, participants read that women at the same hierarchical position as themselves would benefit from this policy. Participants were asked to report their support of the policy for the subgroup they had considered on three items (Kravitz \& Platania, 1993; i.e., "The goals of this policy are good," "I am in favor of applying this hiring policy," and "I would be willing to work at an organization that applies this hiring policy," $\alpha=.91)$. ${ }^{1}$

Demographic variables. Participants provided information about themselves including their age, profession, the organizational level they had reached (subordinate vs. managerial positions), and the years of work experience. The participants reported a variety of different job types and professions in marketing, retail, banking, consulting, legal services, public services, administration, education, health care, pharmaceuticals, and commerce.

\section{Results}

Identification with different subgroups of women. We performed a repeated-measures MANOVA to examine the extent to which women managers versus those subordinates identify with different subgroups of women. The identification with different subgroups of women (successful women in high positions, junior women at the beginning of their career, and women who prioritize their family life) was included as within-participants variable, and participant's hierarchical position (managerial vs. subordinate) as between-participants variable. Results revealed a significant interaction between participant's hierarchical position and the target of identification, $F(1,315)=22.91, p<.001$, Wilks's $\Lambda=.97$.

As can be seen in Table 1 , between-participants comparisons indicate that, compared with women in subordinate positions $(M=4.17, S D=1.52)$, those in

\footnotetext{
${ }^{1}$ For exploratory purposes, we also included additional measures that are not reported here. Outcomes on these measures are consistent with and do not alter the main results reported in the paper.
}

managerial positions $(M=4.98, S D=1.45)$ reported higher identification with other successful women in managerial positions, $(p<.001)$. Also, as predicted, compared to women in subordinate positions $(M=5.29, S D=1.62)$, those in managerial positions $(M=4.62, S D=1.82)$ showed lower identification with women who prioritize their family life over their work, $(p<.005)$. The results revealed no difference between managers $(M=4.51, S D=1.45)$ and subordinates $(M=4.49, S D=1.49)$ with regard to identification with junior female colleagues at the beginning of their career $(p=.91)$.

Additional within-participants comparisons showed that women in managerial positions identified more strongly with other successful women $(M=4.98$, $S D=1.45)$ than with junior women at an early career stage $(M=4.51, S D=1.45),(p<.005)$. Further, women managers identified have the tendency to identify more strongly with other successful women $(M=4.98$, $S D=1.45)$ than those women who prioritize their family life $(M=4.62, S D=1.82, p=.06)$.

Evidence for the QB-phenomenon. Two repeatedmeasures MANOVAs were performed to examine the extent to which women in managerial versus subordinate positions considered themselves as different from the two subgroups of other women in terms of career commitment and masculinity. In both analyses, self versus other ratings were included as withinparticipants variable, and participant's hierarchical position (managerial vs. subordinate) and the target of reference (junior vs. same level women) as between-participants variable.

Career commitment. We observed only a significant main effect of participant's hierarchical position $(F(1$, $315)=8.94, p<.005$, Wilks's $\Lambda=.97)$, but no significant interactions. In line with the QB-phenomenon, between-participants comparisons showed that women in managerial positions $(M=4.36, S D=1.41)$ rated themselves as more career committed than women in subordinate positions $(M=3.34, S D=1.45)$ rated themselves (regardless of the experimental condition; $p<.001)$.

In addition, and this was not anticipated, withinparticipants comparisons showed that compared to respondents in subordinate positions $(M=3.89, S D=1.53)$, women in managerial positions $(M=4.31, S D=1.37)$ also gave higher ratings of the career commitment of 
other women (regardless of whether they were at the same level or at an early career stage; $p=.03$ ).

Masculinity. Results revealed a significant effect of participant's hierarchical position, $F(1,315)=23.54$, $p<.001$, Wilks's $\Lambda=.93$, which as anticipated was qualified by a significant interaction between participant's hierarchical position and their target of reference, $F(1,315)=7.76, p<.01$, Wilks's $\Lambda=.98$.

Consistent with the QB-phenomenon, betweenparticipants comparisons indicated that women in managerial positions $(M=4.76, S D=1.28)$ presented themselves as more masculine than women in subordinate positions $\operatorname{did}(M=3.36, S D=1.35)$ (regardless of the experimental condition; $p<.001)$.

Furthermore, within-participants comparisons showed that women in managerial positions $(M=5.00$, $S D=1.09$ ) rated themselves as more masculine than they rated junior women $(M=4.47, S D=1.15),(p=.03$; Table 2). However, when women managers rated other female colleagues at the same organizational level, there was no significant difference between how they perceived themselves $(M=4.55, S D=1.41)$ and these other women $(M=4.68, S D=1.30 ; p=.59)$. Among women in subordinate positions, we found the opposite effect: They rated other women in the organization-junior women $(M=4.46, S D=1.20)$ as well as those at the same level $(M=3.87, S D=1.34)$-as more masculine than themselves $(M=3.40, S D=1.33 ; M=3.32, S D=1.37$, junior women, same level women condition, respectively $(p<.001$, for both conditions $))$. We elaborate on this unanticipated effect in the General Discussion.

Support for gender quotas. We examined support for gender quotas targeting different subgroups of women, by conducting a $2 \times 2$ ANOVA with participant's hierarchical position (managerial vs. subordinate positions) and the target of reference (junior vs. same level women ${ }^{2}$ ) as between-participants variables. We observed no significant main effects, but the predicted interaction between participant's hierarchical position and the target of the policy was significant,

\footnotetext{
${ }^{2}$ We have checked whether there is an overlap between these two target groups (target junior women condition and target same level women condition) in the case of female subordinates. We did this by examining the years of work experience reported by female subordinates. This revealed that they had on average over 22 years of work experience. Only four participants reported to have 3 years of work experience or less. This implies that as a group these women hold jobs at subordinate positions in the organization, after many years in their professional career. For them, junior women at the beginning of their career represent a different group than women working at the same level—who like themselves may be many years into their professional career. Thus, both the way we instructed research participants in describing the different target groups and the observation that most of the women in subordinate positions that we examined are quite advanced in their professional career in terms of years of experience attest to the fact that junior women (at the beginning of their career) and women at the same level represent two distinct target groups, also for women working in subordinate positions.
} 
$F(1,315)=10.76, p<.001, \eta_{2}{ }^{p}=0.03$. The relevant means and between-participants comparisons indicated a QB effect, with women in managerial positions $(M=3.56, S D=1.48)$ being less supportive of a policy supporting junior women at an early career stage than were women in subordinate positions $(M=4.14$, $S D=1.65 ; p=.04)$. However, women in managerial positions $(M=4.21, S D=1.59)$ responded more positively than women in subordinate positions $(M=3.52$, $S D=1.53)$ toward policies targeting women at the same organizational level $(p=.01)$.

\section{Discussion}

Results of this study reveal that QB-responses should not be seen as indicating a generic competitiveness among women managers, nor do these responses indicate a tendency to devalue or fail to support other women in general. By contrast, this study is the first to show that QBs distinguish between different subgroups of women and do not distance themselves from all women alike. That is, they did not distance themselves from women at the same hierarchical rank and rated them as equally masculine as themselves. Similarly, whereas women in managerial positions were reluctant to endorse gender quotas targeting junior female colleagues, they were happy to support gender quotas targeting female colleagues at the same level-even if those are likely to be their direct competitors. These results suggest that QB-responses emerge exclusively when considering women at lower ranks in the organization. Consistent with prior research, we found that compared to women in subordinate positions, those in managerial positions were more inclined to distance themselves from junior women by rating their own masculinity as higher compared to this subgroup of women (see also Derks, Ellemers, et al., 2011; Derks, Van Laar, et al., 2011).

The present results also nuance prior work suggesting that QBs are women who do not identify with other women at work. That is, this study more specifically established that women in managerial positions distance themselves from more junior women but may still identify with women who resemble them in terms of their professional position and priorities in life. Specifically, the present results revealed that women in managerial positions were inclined to identify more strongly with other women who have been successful in their career than with junior women or those who prioritize their family over their career. These findings suggest that women in managerial positions are more likely to define the self as belonging to a particular subgroup of women (i.e., successful women) rather than thinking of themselves as exceptional individuals who are different from all other women.

\section{Study 2}

Study 1 provides evidence that women in managerial positions only distance themselves from junior female colleagues but they identify with and support women at their own hierarchical level. Yet, it remains unclear whether self-group distancing responses characterize successful women in particular or can be observed among female and male managers alike. Most research on the QB-phenomenon has focused on women exclusively without examining whether these responses are indeed specific to women at work or whether men distance themselves from other junior men in a similar way as they advance on the organizational ladder. The main goal of Study 2 therefore is to compare responses of women and men in managerial positions to those of their counterparts in subordinate positions and test for the existence of an AM phenomenon that mirrors the QB-effect.

\section{Participants and Design}

Participants were 277 employees (163 women; 114 men, age 20 to $63 ; M=40.01, S D=11.36$ ) from different sectors in the French part of Switzerland. They were contacted at their workplace and were asked to complete an online survey (20-30 minutes). In terms of hierarchical position, 103 participants were in managerial positions; 174 participants, in subordinate positions; and on average they reported 18 years of work experience. The study consisted of a 2 (gender: women vs. men) $\times 2$ (participants' hierarchical position: subordinate vs. managerial positions) between-participants design. Unfortunately, but not surprisingly, this set up resulted in unequal cell sizes, $\chi^{2}(1, N=277)=32.63$, $p<.001$. Of the 103 participants in managerial positions, only 38 were female (vs. 65 men). Moreover, of the 174 participants in subordinate positions, 125 were female (vs. 49 men). These cell sizes potentially pose a problem when performing a factorial ANOVA because gender and hierarchical positions are confounded (as they are in reality). When analyzing the data, we took appropriate measures to guard against this (see Discussion for more details).

\section{Measures}

Identification with different subgroups of same-gender colleagues. As in Study 1, we assessed identification with junior same-gender colleagues in subordinate positions with two items $(r=.54$, $p<.001)$, identification with successful same-gender colleagues in managerial positions with two items $(r=.80, p<.001)$, and identification with samegender colleagues who prioritize their family over their career.

QB/AM responses. With measures identical to those in Study 1, participants were first asked to report their personal career commitment and masculinity $(\alpha=.81$ and $\alpha=.84$, respectively) as well as the career commitment and masculinity of their same-gender junior colleagues at an early career stage $(\alpha=.89$ and $\alpha=.88$, respectively). 
Demographic variables. Participants reported background variables such as gender, age, profession, the organizational level they have reached (subordinate vs. managerial positions), and the years of work experience. As in Study 1, they indicated a broad range of different job types and professions, for instance, in marketing, banking, legal services, public services and administration, education, health care, pharmaceuticals, information technology, journalism, and sales.

\section{Results}

Identification with different subgroups of same-gender colleagues. As in Study 1, we performed a repeated-measures MANOVA with the different targets of identification (successful same-gender colleagues, same-gender junior colleagues at the beginning of their career, and same-gender colleagues who prioritize their family life) as a within-participants variable and participant's hierarchical position (managerial vs. subordinate) and participant's gender (women vs. men) as between-participants variables (see Table 3 for means and between- and withinparticipants' comparisons). Results revealed a significant interaction between participant's hierarchical position and the within-participants variable, $F(1$, 273) $=3.63, p=.03$, Wilks's $\Lambda=.97$.

Examining identification with specific gender subgroups, between-participants comparisons showed no significant differences between women or men in managerial and subordinate positions in terms of identification with same-gender juniors or same-gender coworkers who prioritize their family (all $p \mathrm{~s}<\mathrm{ns}$ ). Consistent with Study 1, however, we did find significant effects on identification with same-gender colleagues who have been successful: Here female managers $(M=5.37$, $S D=1.19$ ) reported stronger identification with successful women compared to women in subordinate positions $(M=4.38, S D=1.66 ; p<.001)$. The identification of female managers $(M=5.37, S D=1.19)$ with successful same-gender colleagues was also higher than in the case of male managers $(M=4.51, S D=1.51 ; p<.01)$.

Additional within-participants comparisons showed that women in managerial positions identified more strongly with other women like themselves in terms of career success $(M=5.37, S D=1.19)$ than with junior women at the beginning of their career $(M=4.83$, $S D=1.47 ; p=.02$ ). Among men in managerial positions, no significant difference was found between the levels of identification with different subgroups of men.

Evidence for the QB and AM phenomena. Two MANOVAs with repeated measures were performed to examine the extent to which women and men in managerial and subordinate positions considered themselves as different from same-gender junior colleagues at an early career stage in terms of career commitment and masculinity.

Career commitment. A MANOVA on the degree to which participants reported to be more strongly committed to their career than their same-gender juniors revealed a significant main effect of position, $F(1,273)$ $=18.94, p<.001$, Wilks's $\Lambda=.94$, which was qualified by a (marginally) significant interaction between position and gender, $F(1,273)=2.82, p=.06$, Wilks's $\Lambda=.98$ (see Table 4 for means and between- and within-participants' comparisons).

Focusing on own career commitment first, consistent with results of Study 1, between-participants comparisons indicated that women in managerial positions $(M=4.61, S D=1.67)$ presented themselves as more committed to their career than did women in subordinate positions $(M=3.52, S D=1.48 ; p<.001)$. For men, self-rated levels of career commitment did not depend on their position in the organization. Male participants reported relatively high career commitment across the board, regardless of whether they worked in a managerial $(M=4.43, S D=1.41)$ or subordinate position $(M=4.07, S D=1.39 ; p=.20)$. Importantly, the self-perceived career commitment of female managers was equally high as among male managers $(p=.55)$.

Addressing the difference in perceived career commitment of the self compared to others, within-participants comparisons showed evidence for the QB effect: Women in managerial positions $(M=4.61, S D=1.67)$ rated their own career commitment as higher than that of samegender junior colleagues $(M=3.87, S D=1.32 ; p=.03)$. Among men, we observed no effect of position in selfother ratings of career commitment $(p=.20)$.

Masculinity. The MANOVA on reported masculinity of the self and of same-gender junior colleagues revealed significant main effects of gender, $F(1,273)$ $=17.56, p<.001$, Wilks's $\Lambda=.94$, and position, $F(1$, $273)=15.94, p<.001$, Wilks's $\Lambda=.95$, which was

Table 3. Results of MANOVAs examining statistical differences for identification with different subgroups of same-gender colleagues as a function of participant's gender (women vs. men) and participant's hierarchical position (managerial vs. subordinate), Study 2

\begin{tabular}{lrrrr}
\hline & \multicolumn{2}{c}{ Women } & \multicolumn{2}{c}{ Men } \\
\cline { 2 - 3 } & Managerial position & Subordinate position & Managerial position & Subordinate position \\
\hline Junior same-gender colleagues & $4.83^{\mathrm{a}}(1.47)$ & $4.67^{\mathrm{a}}(1.58)$ & $4.62^{\mathrm{a}}(1.29)$ & $4.50^{\mathrm{a}}(1.49)$ \\
Successful same-gender colleagues & $5.37^{\mathrm{b}}(1.19)$ & $4.38^{\mathrm{c}}(1.66)$ & $4.51^{\mathrm{a}}(1.51)$ & $4.34^{\mathrm{ac}}(1.34)$ \\
Same-gender colleagues who prioritize family life & $4.95^{\mathrm{abd}}(1.63)$ & $5.30^{\mathrm{d}}(1.77)$ & $4.89^{\mathrm{ad}}(1.60)$ & $4.90^{\mathrm{d}}(1.50)$ \\
\hline
\end{tabular}


Table 4. Results of MANOVAs examining statistical differences of QB/AM responses as predicted by participant's gender (women vs. men) and participant's hierarchical position (managerial vs. subordinate), Study 2

\begin{tabular}{|c|c|c|c|c|}
\hline & \multicolumn{2}{|c|}{ Women } & \multicolumn{2}{|c|}{ Men } \\
\hline & Managerial position & $\begin{array}{c}\text { Subordinate } \\
\text { position }\end{array}$ & Managerial position & $\begin{array}{c}\text { Subordinate } \\
\text { position }\end{array}$ \\
\hline Self-reported career commitment & $4.61^{a}(1.67)$ & $3.52^{\mathrm{C}}(1.48)$ & $4.43^{\mathrm{ab}}(1.41)$ & $4.07^{\mathrm{b}}(1.39)$ \\
\hline Perceived career commitment of same-gender colleagues & $3.87^{\mathrm{c}}(1.32)$ & $4.39^{\mathrm{b}}(1.46)$ & $4.13^{b}(1.32)$ & $4.26^{\mathrm{b}}(1.33)$ \\
\hline Self-reported masculinity & $4.81^{a}(1.18)$ & $3.49^{b}(1.43)$ & $4.82^{a}(1.09)$ & $4.43^{a}(1.41)$ \\
\hline Perceived masculinity of same-gender colleagues & $4.53^{\mathrm{a}}(1.36)$ & $4.53^{a}(1.37)$ & $3.97^{b}(1.06)$ & $4.09^{\mathrm{ab}}(0.84)$ \\
\hline
\end{tabular}

Note: Means with different superscripts differ significantly from one another $(p>.05)$. For each dependent variable, between-participants comparisons are made within rows, and within-participants comparisons are made within columns.

qualified by a (marginally) significant interaction between position and gender, $F(1,273)=3.20, p=.08$, Wilks's $\Lambda=.99$ (see Table 4 for means and betweenand within-participants' comparisons).

Between-participants comparisons indicated that women in managerial positions $(M=4.81, S D=1.18)$ described themselves as more masculine than did women in subordinate positions $(M=3.49, S D=1.43$; $p<.001)$. Again, the self-rated levels of masculinity of men in managerial positions $(M=4.82, S D=1.09)$ did not differ from that of men in subordinate positions $(M=4.43, S D=1.41 ; p=.12)$. Additionally, the selfperceived masculinity of female managers did not statistically differ from that of male managers $(p=.98)$.

Within-participants comparisons showed that men in managerial positions rated their own masculinity $(M=4.82, S D=1.09)$ as higher than they rated the masculinity of junior men $(M=3.97, S D=1.06$; $p<.001)$. The self-perceived masculinity of women in managerial positions did not statistically differ from that of junior women $(p=.29)$. More interesting, evidencing a QB effect as well as an AM effect, the participants in managerial positions, regardless of their gender, rated their own masculinity $(M=4.81$, $S D=1.12)$ as higher than that of their same-gender junior colleagues $(M=4.17, S D=1.20 ; p<.005)$. Interestingly, an effect of position was observed for junior women, but not for men. More concretely, female participants in subordinate positions $(M=3.49, S D=1.43)$ rated themselves as less masculine compared to their junior colleagues $(M=4.53, S D=1.37 ; p<.001)$. No significant difference was found among male subordinates $(p=.17)$.

\section{Discussion}

Study 2 confirmed that QB-reactions should not be seen as indicating a particularly competitive attitude of women managers toward other women, as similar AM-behaviors are also observed among male managers. We again found evidence of the QB-phenomenon, in that the self-ratings of women in managerial positions are more career committed and more masculine than the self-ratings of women in subordinate positions. In addition, female managers consider their own career commitment as higher than the career commitment of junior women at an early career stage. However, the comparison we made with the responses of male managers toward their same-gender colleagues reveals that these QB-responses do not necessarily reveal something about the competitive nature of women at work. Instead, successful women seem to respond in just the same way as successful men do.

Indeed, we find no evidence that women who have been successful at work are or have become especially competitive toward other women. Instead, competitiveness toward others emerges as a characteristic of career advancement more generally, as the way women managers view same-gender junior colleagues does not differ from the way men at work respond to each other. These results demonstrate that the group that actually stands out in this comparison is the women at subordinate positions in the organization; female managers respond just like all men do at work. The real reason that responses of female managers are considered so remarkable may thus be that competitiveness is less expected from women, even in the workplace where this is a norm for career advancement (see also Rudman $\delta$ Glick, 1999).

Further, the observations of this study help explain the underlying process of the QB-phenomenon by differentiating between levels of identification with different subgroups of same-gender colleagues. The results provide insight into the ways successful women negotiate between gender and professional identity. Compared to their male colleagues, women in managerial positions were more inclined to identify with other successful women. As members of a low-status gender group, women in managerial positions thus convey the solidarity between the self and other similar successful women, while distancing themselves from women who most resemble the gender stereotype. By contrast, men are not confronted with gender-specific expectations concerning their leadership attributes as male traits can be considered as default and desirable traits for all men at work.

\section{General Discussion}

This work complements and extends prior research on the QB-phenomenon. First, we provided new evidence 
that helps understand the origins and nature of the QB-phenomenon by assessing how women and men identify with different subgroups of same-gender colleagues as a function of their hierarchical position and their life choices. Study 1 revealed that, rather than being disidentified with all women at work, female managers showed a more specific pattern of low identification with women who prioritized family over work. At the same time, they maintained high identification with other successful women like themselves. Further, women managers showed self-group distancing, as they presented themselves as more committed (Study 1) and more masculine (Studies 1 and 2) compared to other women and were reluctant to support gender equality policies. However, they only displayed these QBresponses toward junior women at the beginning of their career. By contrast, they did not consider themselves as different from female colleagues at the same organizational level as themselves and supported gender quotas targeting this subgroup of women. These results suggest that displays of QB-responses among successful women should not be seen as an indicator of their competitive character or general reluctance to support other women at work. Instead, the present work has revealed that, while showing QB-responses toward some subgroups of women, female managers will and do support other women who they think are worthy of such support.

Second, we extended prior work on the QBphenomenon by directly comparing QB-responses among women managers to AM responses of men in similar positions. The findings thus obtained reveal that self-views as being different from same-gender junior colleagues are not related to gender, but to organizational position. That is, female and male managers showed similar levels of career commitment and masculinity. This suggests that women managers do not respond in an exceptional way when compared to men in the same position at work. Responses displayed by women only seem exceptional when compared to women at subordinate positions-or the gender stereotype. In fact, male managers described themselves as distinct from other men in terms of masculinity. These findings are important because they put the QB-phenomenon in perspective: Women in high places are not the exception, but women in subordinate positions act differently from their male colleagues, as they show more modesty in terms of their commitment and masculinity compared to their same-gender colleagues. This is also what we observed in Study 1, where women in subordinate positions described all other women in the organization as more masculine than the self.

These results reveal that whereas men generally emphasize their personal qualities relative to those of other men at work and tend not to identify strongly with their same-gender coworkers regardless of their position, women managers have the tendency to identify more strongly with other successful women. The present results also suggest that one reason for why QBs are judged so negatively is that their behavior does not conform to what is expected of women, enhanced gender-identifying behavior and selfmodesty that characterizes women at lower organizational levels.

\section{Practical Implications for Diversity}

Together, these findings shed light on the challenges of improving gender diversity in the workplace. First, it has to be acknowledged that female managers are particularly strict when evaluating junior women, but they tend to acknowledge the efforts made by other women having reached the same stage in their career. This implies that having women in managerial positions will not necessarily be helpful to other women at an early career stage. However, for women in senior positions, the presence of other successful women may be a source of support and solidarity as reflected in their high levels of identification with them. Moreover, whereas senior women often tend to be judged quite negatively because they violate gender role expectations (see also Rudman \& Glick, 1999), our results suggest that these senior women will support each other, creating a climate in which senior women are more likely to be able to cope with rejection and negative evaluations they may encounter in their interactions with men or with junior women (see also Schmitt, Branscombe, Kobrynowicz, \& Owen, 2002).

Second, diversity policies may benefit from the observations made in Study 1 -that junior women overestimate the career commitment of other junior women relative to the self-and Study 2-that junior women but not men consider themselves as less career committed and less masculine than their same-gender colleagues. These findings suggest that junior women tend to devalue their own professional ambitions, agency, and commitment relative to others in the workplace. This suggests that the biggest challenge for diversity management may be to address the reluctance of women at the early stage of their career to value or express their own career commitment. Hence, efforts to enhance the representation of women in managerial positions should take into account the ambitiondepressing effects for women of perpetuating a masculine organizational culture, especially at early career stages (Derks, Van Laar, \& Ellemers, 2006). Such efforts may benefit from prior research revealing strategies that help buffer against the threat and motivation and performance loss of gender-stereotypical expectations (Derks, Scheepers, Van Laar, \& Ellemers, 2011; Derks, Van Laar, \& Ellemers, 2007a, 2007b, 2009).

We do note that the data reported here remain subject to a limitation because of the unbalanced cellsizes in our design. It turned out to be much harder to find women managers than women subordinates to respond to our questionnaire-even if this reflects the actual representation of these groups of women in work organizations. To guard against the possibility that the conclusions we draw from these data are flawed as a 
result of this, we conducted additional analyses on a more balanced sample, created by randomly reducing the number of women in subordinate positions. Importantly, this additional analysis produced the same pattern of results, enhancing confidence in the validity of our conclusions.

\section{Conclusion}

Previous research has focused on negative aspects of the QB-phenomenon, showing how women in high positions distance themselves from junior women and legitimize the current status quo of gender inequality at work. These prior studies have been interpreted as suggesting that QBs are solitary and are unwilling to support other women. However, our current findings demonstrate that this interpretation is incorrect: QBs do not distance themselves from or compete with all other women. The present data reveal that they do identify with and support women who have also succeeded in their career. Importantly, comparing responses of male and female managers further revealed that self-distancing QB-responses are not at all unique for women in managerial positions: male managers also distance themselves from other junior men, and all men show AM tendencies at work.

\section{References}

Barreto, M., \& Ellemers, N. (2013). Sexism in contemporary societies: How it is expressed, perceived, confirmed, and resisted. In M. K. Ryan \& N. R. Branscombe (Eds.), The Sage handbook of gender and psychology (pp. 289-305). London, UK: Sage.

Barreto, M., Ryan, M. K., \& Schmitt, M. T. (2009). The glass ceiling in the 21st century: Understanding barriers to gender equality. Washington, DC: American Psychological Association.

Bem, S. L. (1974). The measurement of psychological androgyny. Journal of Consulting and Clinical Psychology, 42, 155-162. http://dx.doi.org/10.1037/h0036215

Derks, B., Ellemers, N., Van Laar, C., \& de Groot, K. (2011). Do sexist organizational cultures create the queen bee? British Journal of Social Psychology, 50, 519-535. http://dx. doi.org/10.1348/014466610X525280

Derks, B., Scheepers, D., Van Laar, C., \& Ellemers, N. (2011). The threat vs. challenge of car parking for women: How self- and group affirmation affect cardiovascular responses. Journal of Experimental Social Psychology, 47, 178-183. http://dx.doi.org/10.1016/j.jesp.2010.08.016

Derks, B., Van Laar, C., \& Ellemers, N. (2006). Striving for success in outgroup settings: Effects of contextually emphasizing ingroup dimensions on stigmatized group members' social identity and performance styles. Personality and Social Psychology Bulletin, 32, 576-588. http://dx. doi.org/10.1177/0146167205283336

Derks, B., Van Laar, C., \& Ellemers, N. (2007a). Social creativity strikes back: Improving low status group members motivation and performance by valuing ingroup dimensions. European Journal of Social Psychology, 37, 470-493. http://dx.doi.org/10.1002/ejsp.375
Derks, B., Van Laar, C., \& Ellemers, N. (2007b). The beneficial effects of social identity protection on the performance motivation of members of devalued groups. Social Issues and Policy Review, 1, 217-256. http://dx.doi.org/10.1111/ j.1751-2409.2007.00008.x

Derks, B., Van Laar, C., \& Ellemers, N. (2009). Working for the self or working for the group: How self- vs. groupaffirmation affect collective behavior in low status groups. Journal of Personality and Social Psychology, 96, 183-202. http://dx.doi.org/10.1037/a0013068

Derks, B., Van Laar, C., \& Ellemers, N. (in press). The Queen Bee Phenomenon: Why women leaders distance themselves from junior women. The Leadership Quarterly. http://dx.doi.org/10.1016/j.leaqua.2015.12.007

Derks, B., Van Laar, C., Ellemers, N., \& De Groot, K. (2011). Gender bias primes elicit queen bee responses among senior police women. Psychological Science, 22, 1243-1249. http://dx.doi.org/10.1177/0956797611417258

Derks, B., Van Laar, C., Ellemers, N., \& Raghoe, G. (2015). Extending the queen bee effect: How Hindustani workers cope with disadvantage by distancing the self from the group. Journal of Social Issues, 71, 5-21. http://dx.doi.org/ $10.1111 /$ josi. 12124

Ellemers, N. (2014). Women at work: How organizational features impact career development. Policy Insights from Behavioral and Brain Sciences, 1, 46-54. http://dx.doi.org/ $10.1177 / 2372732214549327$

Ellemers, N., De Gilder, D., \& Van den Heuvel, H. (1998). Career-oriented versus team-oriented commitment and behavior at work. Journal of Applied Psychology, 83, 717-730.

Ellemers, N., Rink, F., Derks, B., \& Ryan, M. (2012). Women in high places: When and why promoting women into top positions can harm them individually or as a group (and how to prevent this). Research in Organizational Behavior, 32, 163-187. http://dx.doi.org/ 10.1016/j.riob.2012.10.003

Ellemers, N., van den Heuvel, H., de Gilder, D., Maass, A., \& Bonvini, A. (2004). The underrepresentation of women in science: Differential commitment or the queen bee syndrome? British Journal of Social Psychology, 43, 1-24. http://dx.doi.org/10.1348/0144666042037999

Faniko, K. (2015). Genre d'accord, mérite d'abord? Une analyse des opinions envers les mesures de discrimination positive [Gender ok, but merit first? An analysis of opinions towards affirmative action plans]. Bern, Germany: Peter Lang.

Faniko, K., Lorenzi-Cioldi, F., Buschini, F., \& Chatard, A. (2008). Affirmative action plans that assist women's mobility in Albania: The paradox of education. In S. Fischer $\delta \mathrm{H}$. Pleines (Eds.), Crises and conflicts in post-socialist societies. The role of ethnic, political and social identities in changing Europe (Vol. 4, pp. 209-219). Stuttgart, Germany: Ibidem. Faniko, K., Lorenzi-Cioldi, F., Buschini, F., \& Chatard, A. (2012). The influence of education on attitudes towards affirmative action: The role of the policy's strength. Journal of Applied Social Psychology, 42, 387-413. http://dx.doi.org/ 10.1111/j.1559-1816.2011.00892.x

Faniko, K., Lorenzi-Cioldi, F., Ghisletta, P., Sørensen, S. Ø., Manushi, E., Shalsi, F., Chipeaux, M. (2015). When the meritocracy opposes quota policy: How education and policy strength impact opinions on affirmative action. In K. Faniko, F. Lorenzi-Cioldi, O. Sarrasin, \& E. Mayor 
(Eds.), Gender and social hierarchies: Perspectives from social psychology (pp. 82-97). London, UK: Routledge.

Kravitz, D. A., \& Platania, J. (1993). Attitudes and beliefs about affirmative action: Effects of target and of respondent sex and ethnicity. Journal of Applied Psychology, 78, 928-938. http://dx.doi.org/10.1037/0021-9010.78.6.928

Ng, C. W., \& Chiu, W. C. K. (2001). Managing equal opportunities for women: Sorting the friends from the foes. Human Resource Management Journal, 11, 75-88. http://dx.doi.org/ 10.1111/j.1748-8583.2001.tb00033.x

Rudman, L. A., \& Glick, P. (1999). Feminized management and backlash toward agentic women: The hidden costs to women of a kinder, gentler image of middle-managers. Journal of Personality and Social Psychology, 77, 1004-1010. http://dx.doi.org/10.1037/a0018304
Schmitt, M. T., Branscombe, N. R., Kobrynowicz, D., \& Owen, S. (2002). Perceiving discrimination against one's gender group has different implications for well-being in women and men. Personality and Social Psychology Bulletin, 28, 197-210. http:// dx.doi.org/10.1177/0146167202282006

Sheppard, L. D., \& Aquino, K. (2013). Much ado about nothing? Observers' problematization of women's same-sex conflict at work. Academy of Management Perspectives, 27, 52-62. http://dx.doi.org/10.5465/amp.2012.0005

Tajfel, H., \& Turner, J. C. (1986). The social identity theory of intergroup behavior. In S. Worchel \& W. G. Austin (Eds.), The psychology of intergroup relations (pp. 7-24). Chicago, IL: Nelson-Hall. 